\title{
Evaluation of IPSI-lateral versus CONTRA-lateral TRAM flap survival with static thermography in pedicled flap breast reconstruction
}

\author{
by J. Jankau *, M. Moderhak** and Sz. Kołacz*
}

\author{
* Department of Plastic Surgery, Medical University of Gdańsk, ul. Debinki 7, 80-211, Gdańsk, \\ jjankau@gumed.edu.pl \\ ** Department of Biomedical Engineering, Gdańsk University of Technology, ul. Narutowicza 11/12, 80-233 \\ Gdańsk
}

Acknowledgement: This work has been partially supported by Statutory Funds of Electronics, Telecommunications and Informatics Faculty, Gdansk University of Technology

\begin{abstract}
Since 1982 the pedicled TRAM flap has become the "gold standard" in breast reconstruction procedures. It has also been debated since then which way of transferring the tissue island is more reliable with less complications IPSI vs CONTRA [1]. The reasons for complications include the manner of twisting the nourishing blood supply and the tension due to the distance of the pedicle in IPSI or CONTRA procedures [2]. Static thermography seems to provide the solution. In our experiment we measure medial surface temperature of flaps using static thermography. The results were compared against the number of flap failures in each type of reconstruction. The study was conducted on a group of 20 female patients who underwent breast reconstruction.
\end{abstract}

\section{Introduction}

Among the most common plastic surgery methods used in breast reconstructions is using pedicled flaps, for instance the skin-muscle TRAM flap. Despite the fact that its anatomy is well-explored [3] its necrosis may develop as a consequence of twisting and tension on the nourishing blood supply. In order to minimalize the risk of flap failure some surgeons decide to use IPSI lateral flap which involves less tension but more flap pedicle rotation. On the other hand, other surgeons use the CONTRA-lateral flap with more tension but less rotation of flap pedicle. Hartrampf's original paper presents the use of TRAM IPSI flap [4]. Nowadays both CONTRA and IPSI flaps are used, and the choice depends on the surgeon's experience and patient's anatomy. Available literature refers to reports on the impact of tension and rotation of the vascular pedicle on the flap blood supply, suggesting more favourable conditions provided by IPSI flaps [2]. It is, however, impossible to overlook the reports on the lack of significant differences between IPSI and CONTRA flaps [5].

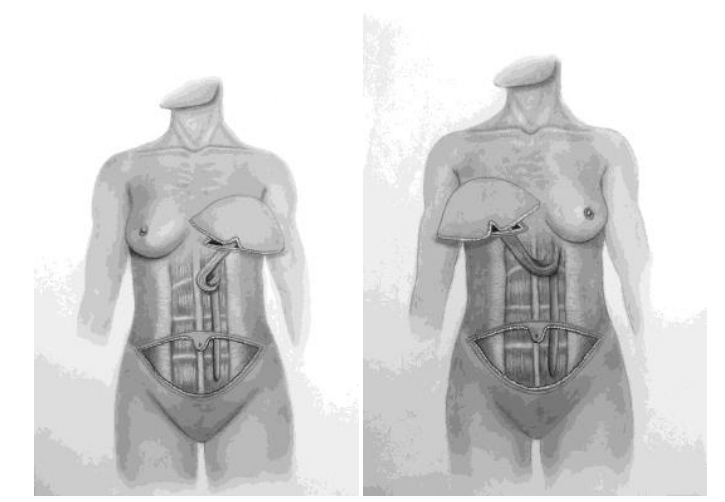

Fig. 1. IPSI-lateral and CONTRA-lateral TRAM flap 


\subsection{1/qirt.2016.047}

\section{Problems}

Adequate preoperative planning is an essential part of reconstructive surgery. In order to minimalize the risk of flap failure it is essential to choose the flap with better blood perfusion. The aim of our research was to compare the images generated in intraoperative static thermography both prior to and after twisting the vascular pedicle of the flap, and in subsequent postoperative days in the reconstructive procedures with TRAM IPSI and CONTRA flaps. Knowing the fact that the relationship between skin blood perfusion and temperature is well known we decided to examine it with a static thermograph device [6].

\section{Methods and results}

The study involved a group of 20 patients undergoing TRAM flap breast reconstruction. Half of them underwent IPISI lateral breast reconstruction and other half CONTRA lateral. All treatments were provided by the same operating team. Each patient was examined preoperatively (b2, b3), on postoperative day 1 (b4), 7 (b5), 30 (b6) and 90 (b7) surgery with static thermography device, and the results and the number of flat failure instances were compared between groups. This paper presents the results of the intraoperative examination performed after flap dissection, after transferring the flap to the recipient site and twisting the vascular pedicle, and on the first and seventh postoperative day. The results indicate that the mean intraoperative temperature and median of IPSI flaps are higher than those of CONTRA flaps, which suggests better blood supply to the flap [6] and corroborates the results of Clugston's research [2]. The visible results are reversed on the first and the seventh day, and the mean temperature as well as CONTRA flap median are distinctly higher. As there are no published reports on the subject-matter, we cannot refer to them. We think the reason for the result is a higher number of flaps with the peripheral necrosis in the IPSI group, which contributed to decreasing the mean value of temperature in the whole group. It confirms the conclusions in [7] indicating that intraoperative static thermography cannot provide imaging of potential peripheral necrosis of a flap and lesions are visible as late as on the first postoperative day.

\begin{tabular}{|c|c|c|c|c|}
\hline IPSI & b-2 & b-3 & b-4 & b-5 \\
\hline $\begin{array}{l}\text { Mean Temp. } \\
\text { mean (SD) }\end{array}$ & $303,2(0,9)$ & $302,4(1,5)$ & $305,8(1,6)$ & $305,7(1,2)$ \\
\hline $95 \% \mathrm{CI}$ & {$[302,5 ; 303,9]$} & {$[301,3 ; 303,5]$} & {$[304,4 ; 307,2]$} & {$[304,7 ; 306,7]$} \\
\hline $\begin{array}{r}\text { range (min- } \\
\max )\end{array}$ & $301,3-304,1$ & $300,4-304,5$ & $304,0-308,1$ & $304,0-308,1$ \\
\hline Median & 303,4 & 302,4 & 305,9 & 305,5 \\
\hline CONTRA & b-2 & b-3 & b-4 & b-5 \\
\hline $\begin{array}{l}\text { Mean Temp. } \\
\text { mean (SD) }\end{array}$ & $301,0(0,8)$ & $301,7(2,5)$ & $307,0(1,0)$ & $307,5(1,2)$ \\
\hline $95 \% \mathrm{CI}$ & {$[300,4 ; 301,7]$} & {$[299,9 ; 303,6]$} & {$[306,3 ; 307,8]$} & {$[306,7 ; 308,3]$} \\
\hline $\begin{array}{r}\text { range (min- } \\
\text { max) }\end{array}$ & $300,0-302,3$ & $298,6-306,1$ & $305,7-308,8$ & $306,2-310,3$ \\
\hline median & 301,0 & 301,1 & 307,1 & 307,6 \\
\hline
\end{tabular}

Tab. 1 Results of static thermography on subsequent days 
10.21611/qirt.2016.047

\begin{tabular}{|l|l|l|l|}
\hline & IPSI & CONTRA & MICRO \\
\hline Total number & 10 & 10 & 18 \\
\hline Partial flap necrosis & 4 & 1 & 4 \\
\hline
\end{tabular}

Tab. 2 Total number of reconstructions with the number of complications in particular groups

Considering available research results, we are not able to determine by means of static thermography which type of pedicle twisting is more favourable in terms of flap perfusion. Each surgeon should take his or her own experience and expertise into consideration while selecting the method which is appropriate to a particular patient and can offer the best aesthetic effect. What is more, we think that further research is necessary to explore the issue presented in this paper.

\section{REFERENCES}

[1] Clugston PA, Gingrass MK, Azurin D, Fisher J, Maxwell GP. "Ipsilateral pedicled TRAM flaps: the safer alternative?" Plast Reconstr Surg. 105(1):77-82. Jan 2000

[2] Clugston PA, Lennox PA, Thompson RP. "Intraoperative vascular monitoring of ipsilateral vs. contralateral TRAM flaps.” Ann Plast Surg. 41(6):623-8 Dec 1998.

[3] Moon HK, Taylor GI. "The Vascular Anatomy of Rectus Abdominis Musculocutaneous Flaps Based on the Deep Superior Epigastric System". Plast Reconstr Surg Vol. 82, No. 51998.

[4] Hartrampf CRJr, Scheflan M, Black PW. "Breast reconstruction with a transverse abdominal island flap". Plast Reconstr Surg. 69;216-225, 1982.

[5] T.A. Janiga, D.M. Atisha, I.F. Lytle, E.G. Wilkins, A.K. Alderman. "Ipsilateral pedicle TRAM flaps for breast reconstruction: are they as safe as contralateral techniques?". Journal of Plastic, Reconstructive \& Aesthetic Surgery Volume 63, 322-326, 2010.

[6] Francis JE, Roggli RI, Love TJ. "Thermography as means of blood perfusion measurement". J Biomech Eng; 101; 246-251, 1979

[7] Kołacz Sz, Moderhak M, Jankau J. „The use of the static thermography in monitoring flap perfusion in breast reconstruction with TRAM flap". Quantitative InfraRed Thermography Conference 2016 